\title{
The potential function of microRNAs as biomarkers and therapeutic targets in multiple myeloma (Review)
}

\author{
BINGYING ZHU ${ }^{1}$, SHAOQING JU ${ }^{1}$, HAIDAN CHU ${ }^{1}$, XIANJUAN SHEN ${ }^{2}$, YAN ZHANG ${ }^{1}$, XI LUO ${ }^{1}$ and HUI CONG $^{1}$ \\ ${ }^{1}$ Laboratory Medicine Center; ${ }^{2}$ Surgical Comprehensive Laboratory, \\ Affiliated Hospital of Nantong University, Nantong, Jiangsu 226000, P.R. China
}

Received September 8, 2016; Accepted January 10, 2018

DOI: $10.3892 / \mathrm{ol} .2018 .8157$

\begin{abstract}
Multiple myeloma (MM), accounting for $\sim 1 \%$ of all types of human cancer and $13 \%$ of all hematological malignancies, is characterized by the malignant proliferation of monoclonal plasma cells (PCs) in the bone marrow. MM leads to end stage organ impairment, including bone lesions, renal dysfunction, hypercalcemia and anemia. So far, the specific pathogenesis of MM remains unclear and no early-stage sensitive biomarker of MM has been well characterized. Furthermore, treating MM is difficult, as the majority of patients eventually relapse or become refractory following treatment using presently available methods. To date, a number of studies have demonstrated that microRNAs (miRNAs) may serve crucial functions in the progression of numerous cancers, including MM. During the tumorigenesis and pathogenesis of MM, there are multiple carcinogenic events that involve the pernicious transformation from normal to malignant PCs. miRNAs, as oncogenes or tumor suppressors, regulate MM progression-related signaling pathways. In the present review, the up-to-date preliminary basic studies and associated clinical works on the underlying mechanisms of aberrant miRNA profiling in MM have been summarized, including an evaluation of its value as a potential biomarker and a novel therapeutic strategy for MM.
\end{abstract}

\section{Contents}

1. Introduction

2. miRNAs deregulated in MM

3. miRNAs as potential diagnostic biomarkers of MM

4. miRNAs as potential prognostic biomarkers of MM

5. miRNA-based therapeutic strategies in MM

6. Conclusion

Correspondence to: Professor Hui Cong, Laboratory Medicine Center, Affiliated Hospital of Nantong University, 20 Xisi Road, Nantong, Jiangsu 226000, P.R. China

E-mail: huicjs@163.com

Key words: multiple myeloma, microRNAs, biomarkers, diagnosis, prognosis, targets, therapy

\section{Introduction}

Multiple myeloma (MM) is the second most common cause of hematological malignancy-associated mortality in America, second only to non Hodgkin's lymphoma (1). The incidence of $\mathrm{MM}$ in Asia is 0.5-1/100,000, whereas the incidence in Africa and America is 10-12/100,000 (2). Generally, the median age of patients diagnosed with MM is 69 years old, and two thirds of patients are male (3). Over the previous two decades, the median survival time of patients with MM has increased from 3 to 6 years due to improvements in available treatments (4). However, the majority of patients have only a several-year remission and will eventually relapse or become refractory, with MM accompanied by severe multiple systemic lesions $(5,6)$.

The pathogenesis of MM includes multistep carcinogenic events. Monoclonal gammopathy of undetermined significance (MGUS), the pre-malignant condition of MM, is typically followed by smoldering myeloma and finally develops into MM (7). A previous report indicated that patients with MGUS progress to MM or other associated malignant tumors at a rate of $1 \%$ per year (8). Therefore, it is important to accurately classify the different stages of MM to identify early stage and high-risk patients to enable timely clinical intervention (9).

At present, the treatment for MM includes autologous stem cell transplantation (ASCT) and the combined application of multiple chemotherapeutic drugs $(10,11)$. However, there are a number of limitations with present therapeutic strategies. Firstly, patients with MM have differing responses to the same standardized treatment and drug-resistance may be induced. Secondly, although disease-free survival has been prolonged in patients with $\mathrm{MM}$, the majority relapse eventually and the condition is more complicated following relapse (12). Therefore, uncovering more effective biomarkers and therapeutic agents for MM is desirable (13-15).

MicroRNAs (miRNA/miRs) are small ( 22 nucleotides) non-coding RNAs that are associated with the initiation and progression of tumors by regulating $\sim 30 \%$ genes at a post-transcriptional level (16). Accumulating evidence has demonstrated that miRNAs may be associated with regulating cellular apoptosis, proliferation, differentiation, metabolism, invasion and migration in vitro (17-19). The regulatory mechanisms of miRNAs in tumor cells have been studied extensively and the majority of the results concur that mature miRNAs are loaded into the RNA-induced silencing complex, which 
results in the degradation or translational inhibition of their targets depending on perfect or partial base complementarity with the $3^{\prime}$ untranslated region (UTR) of genes $(20,21)$. This mode of interaction between miRNAs and their target genes in tumor cells means that they possess the potential to become novel therapeutic agents via the knockdown onco-miRs or the restoration of tumor-suppressive (TS)-miRs (22). Additionally, aberrant miRNA expression profiling in MM may be used as a biomarker for tumor classification, grading and clinical outcomes prediction in addition to providing the rationale for clinical individual therapy $(7,23)$.

\section{2. miRNAs deregulated in MM}

$\mathrm{MM}$ is a heterogeneous malignancy with complex genetic abnormalities, including the presence of hypodiploidy, gene mutations, chromosome translocations, amplifications and deletions (24). Emerging evidence demonstrates that the expression of miRNA may be affected by numerous genetic diversities, including genomic alterations (25), transcriptional regulation (26), epigenetic regulation $(27,28)$, RNA editing and sequence variations in miRNA binding sites, including in SNPs (29).

Dysregulated miRNAs in MM often serve similar functions in pathological processes as oncogenes or tumor suppressor genes via the activation of multiple signaling pathways associated with $\mathrm{MM}$, including the nuclear factor $-\kappa \mathrm{B}(\mathrm{NF}-\kappa \mathrm{B})$ signaling pathway (30), interleukin (IL)6/signal transducer and activator of transcription (STAT)3 signaling pathway (31), tumor protein P53 (P53)/mouse double minute 2 homolog signaling pathway (32) and phosphatidylinositide 3-kinases (PI3K)/protein kinase B (AKT) signaling pathway (33). During the occurrence and development of $\mathrm{MM}$, the regulatory mechanisms of these miRNAs also provide the theoretical foundation for clinical-associated application research in the future (Fig. 1).

miRNA expression profiling analyses in MM. Increasingly, evidence suggests that aberrant miRNA expression is a hallmark in patients with MM, and that normal PCs have distinct miRNA expression profiles with malignant PCs. Zhou et al (34) profiled the miRNA expression pattern of syndecan-1 (CD138) ${ }^{+}$cells isolated from 52 newly diagnosed patients with MM and two healthy donors (HDs), and revealed an elevated total miRNA level in malignant PCs. Microarray data analyses demonstrated that 39 miRNAs including miR-18, miR-92a, miR-181a, miR-181b, miR-221 and miR-222 were consistently expressed at higher levels in samples from newly diagnosed cases compared with HDs, whereas only miR-370 was downregulated in MM.

Although MM is a type of cancer that originates from malignant PCs in bone marrow, it also exerts considerable influence on ectopic miRNA expression profiles in body fluid, including serum, plasma, urine etc. Hao et al (35) performed a miRNA expression profile analysis on the serum samples from seven newly diagnosed symptomatic patients with MM and five HDs using the miRCURYTM LNA Array, and the results indicated that amongst all 1,891 miRNAs, 4 miRNAs were upregulated and 23 were downregulated. miR-214 (fold change of 4.80), miR-135b (fold change of 3.60), miR-132 (fold change of 0.43) and miR-92a (fold change of 0.49) among them were selected to be further validated in a large cohort of 108 newly diagnosed patients with MM and 44 HDs by RT-qPCR assay due to their critical function in regulating the differentiation of osteoclasts and osteoblasts as previously reported. Results confirmed that the level of miR-214 (2.34 vs. $0.23, \mathrm{P}=0.0005)$ and miR-135b (1.83 vs. $-0.18, \mathrm{P}=0.0022$ ) were significantly increased in patients with MM compared with HDs. Furthermore, the receiver operating characteristic (ROC) analysis revealed that miR-214 and miR-135b may offer a powerful diagnostic tool for the identification of bone disease related to MM with high sensitivity and specificity.

In general, these previous studies disclosed a series of abnormally expressing miRNAs in patients with MM compared with HDs by high-throughput screening technologies, summarized in Table I (10,35-43). However, the results from these studies do not appear to be consistent. This discrepancy may partly be due to the differences in the platforms used for microarray technologies, the number of miRNAs analyzed, and the types and sizes of the samples included and the statistical methods designed.

In addition to being associated with clinical pathological parameters, a number of these deregulated miRNAs may be involved in the pathogenesis of MM. Global abnormal miRNA expression profiling provide the basis for further investigations on the specific functions of a single miRNA in the pathogenesis of MM. Firstly, further in vitro and in vivo experiments on the function of miRNAs are required to validate their biological function in MM. Subsequently, it is important to determine the potential mRNA targets of the deregulated miRNAs and investigate the underlying mechanism. In previous years, numerous bioinformatic softwares using different computational algorithms have been well developed to predict miRNA targets including TargetScan (http://www.targetscan.org) (44), miRanda (http://www.microRNA.org) (45) and PicTar (http://pictar. mdc-berlin.de/) (46). A number of studies selected the intersection of a number of different software predicted target genes in order to conduct in-depth research. This putative binding relationship should be validated using dual-luciferase reporter assays, the change of luciferase activity will decide whether this miRNA may bind directly to the 3'UTR of its target gene (47).

Functional studies of dysregulated miRNAs in MM. Following the identification of dysregulated miRNAs in MM, an increasing number of studies have emphasized how these small molecules function in the process of transformation from normal PCs to malignant PCs. These studies demonstrate that miRNAs may exert an important function in regulating cell processes (including apoptosis, proliferation, migration and the cell cycle) in MM by directly binding to the corresponding target genes. Table II $(18,36,48-55)$ and Table III $(18,27,33,38,56-71)$ summarize all deregulated miRNAs and their target genes in MM. The understanding of this mode of interaction in MM will lay the theoretical foundation for the clinical miRNA-based therapy.

miR-17-92 cluster. miR-17-92 cluster, located in chromosome 13q31.3, including miR-18a, miR-20a, miR-92, miR-17 and $\mathrm{miR}-19 \mathrm{a} / \mathrm{b}$, is activated by the oncogene MYC proto-oncogene, BHLH transcription factor (C-MYC) and its expression is upregulated in a variety of types of cancer (72). It has previously been verified that an abnormally elevated expression of the miR-17-92 cluster is involved in the malignant progression of MM $(52,73)$. Pichiorri et al (36) reported that the miR-17-92 cluster was 


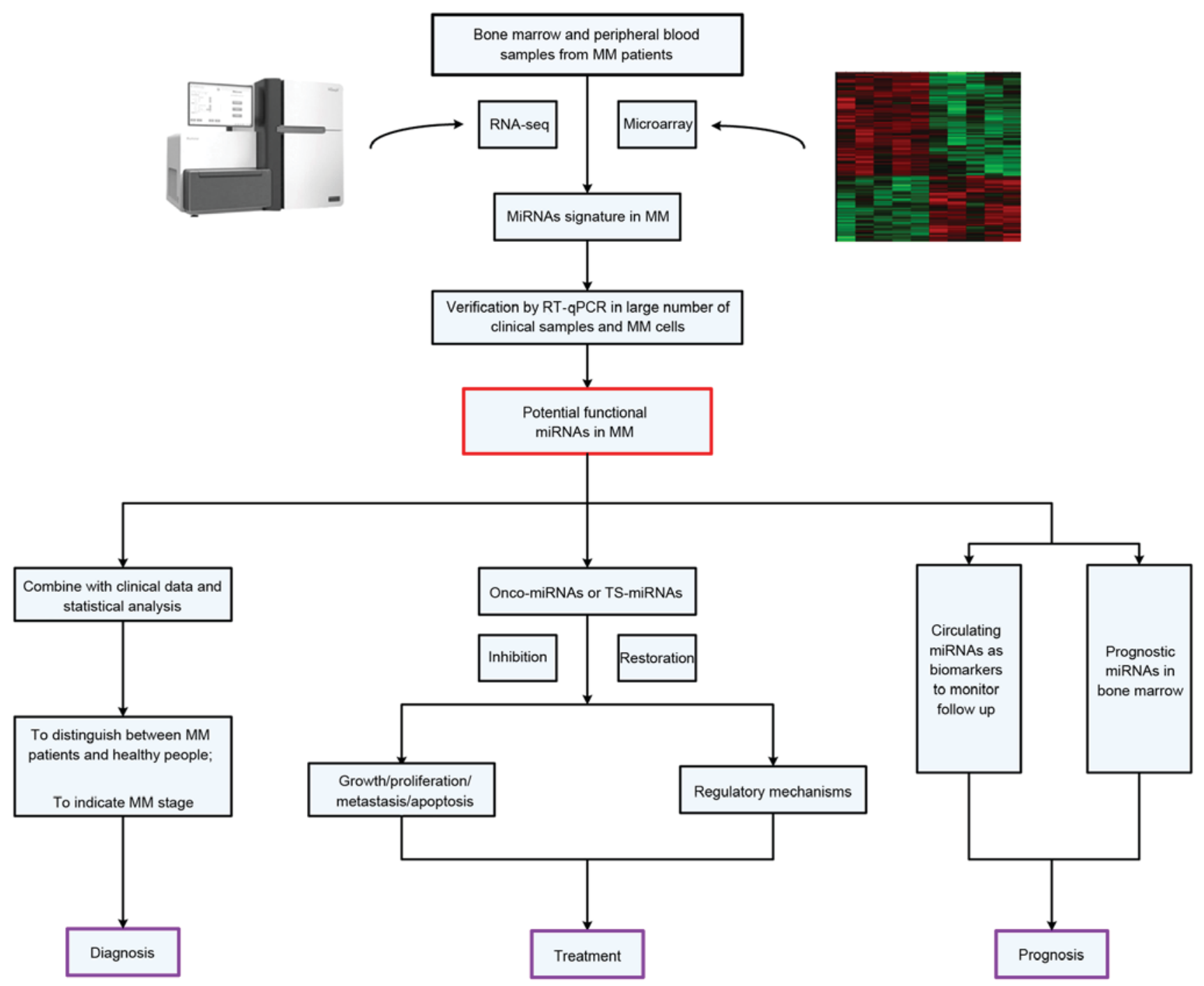

Figure 1. The sourcing, verification and potential applications of miRNAs in clinical-associated application research for MM. MM, multiple myeloma; miRNA, microRNA; RT-qPCR, reverse transcription-quantitative polymerase chain reaction; TS-miRNA, tumor-suppressive miRNA.

significantly increased in the malignant PCs of patients with MM compared with normal ones of HDs. Additionally, the cluster members miR-19a and miR-19b were able to downregulate the protein expression of suppressor of cytokine signaling 1 (SOCS1), and then promote the proliferation of MM cells. It is well acknowledged that SOCS1 is a negative regulator of the signaling pathways mediated by IL6, and the precise mechanism is partially due to the fact that its decreased expression may induce the phosphorylation of signal transducer and activator of transcription 3 (STAT3), eventually resulting in unlimited growth of tumor cells $(31,74)$. Furthermore, it has been revealed that miR-19 targeted the BCL2 like 11 gene and downregulated its protein expression, resulting in reduced apoptosis and the increased proliferation of malignant PCs. Although this cluster has a recognized carcinogenic effect in tumors, studies have also revealed that it may function as a tumor suppressor gene in inhibiting the proliferation in breast cancer cells. Additionally, Gutierrez et al (75) reported that the expression of miR-20a, miR-18a and miR-19b were downregulated in patients with $\mathrm{MM}$ with retinoblastoma gene deletion. It was suggested that this cluster may serve a different function in different subtypes of MM. It is worth mentioning that no abnormal expression of the miR-17-92 cluster is present in MGUS, indicating that the miR-17-92 cluster may participate in the progression from MGUS to MM and has the potential to be used to distinguish MGUS from MM.

miR-29 family. The miR-29 family includes miR-29a, miR-29b and $\mathrm{miR}-29 \mathrm{c}$, have been reported to possess a significant tumor inhibitory effect and are downregulated in hematological malignancies via regulating cell proliferation, differentiation and apoptosis $(76,77)$. Amongst a variety of miRNAs, the miR-29 family represents a prototypical example of epi-miRNAs by targeting epigenetic regulators including DNA methyltransferases (DNMTs). In MM, miR-29b was revealed to target DNMTs, resulting in the demethylation of SOCS1 and an increase of its protein expression. SOCS1 inhibited the phosphorylation of its receptor, then inhibited the activation of STAT3 by binding with Janus Kinase, which finally resulted in the decreased proliferation of MM cells via the suppression of the transcription of downstream genes (61). In addition, miR-29b may also negatively regulate the PI3K/AKT signaling pathway. miR-29b inhibited the phosphorylation of AKT and re-activated suppressed apoptosis-promoting proteins, including P53, BCL2 


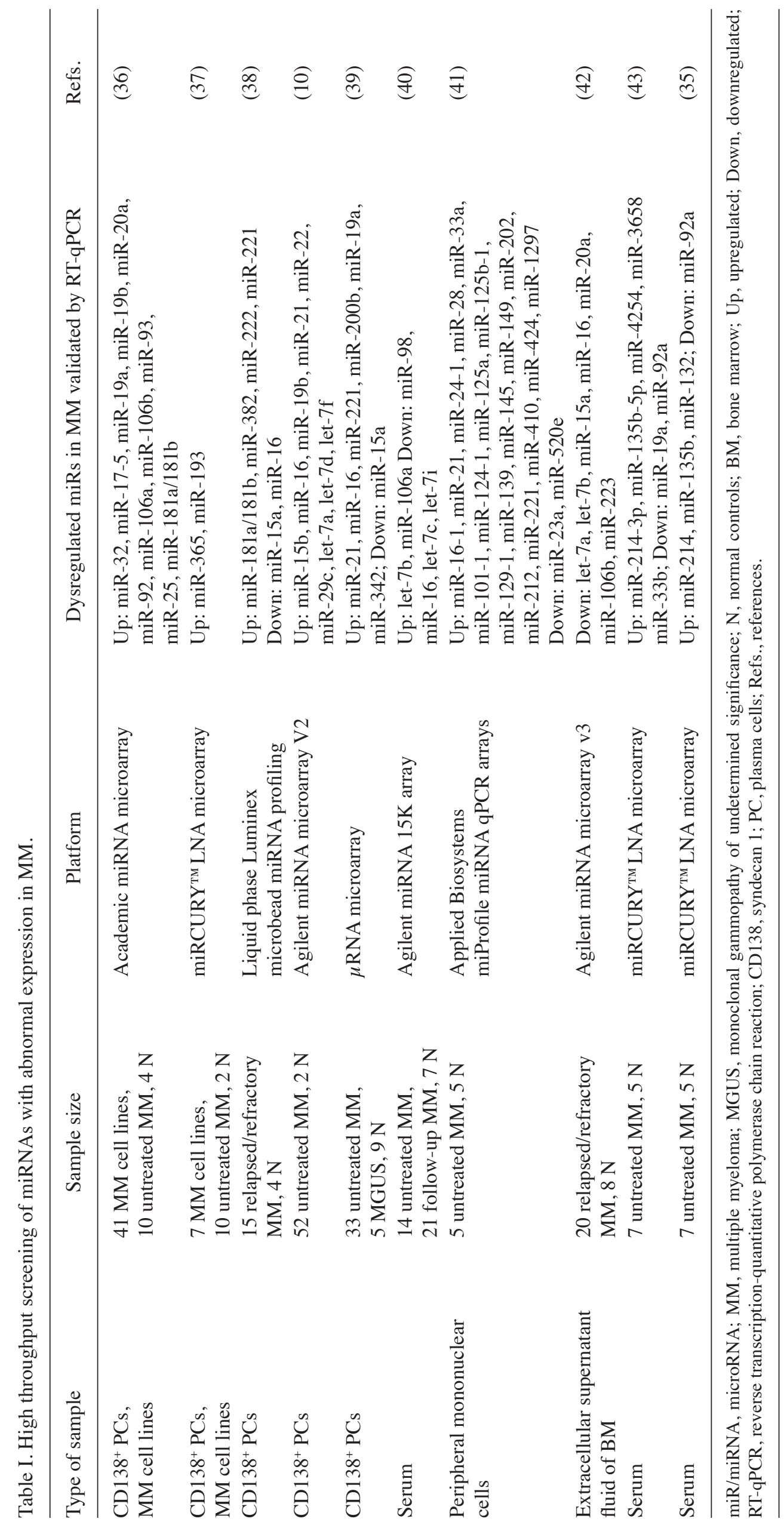


Table II. Principal oncogenic microRNAs with upregulation in MM.

\begin{tabular}{lllr}
\hline MicroRNAs & \multicolumn{1}{c}{ Cell processes } & \multicolumn{1}{c}{ Validated target genes } \\
\hline miR-221/222 & Cell apoptosis, cell proliferation & p27Kip1, p57Kip2, PUMA, PTEN \\
miR-17-92 cluster & Cell apoptosis, cell proliferation & \multicolumn{1}{c}{ BIM, SOCS1, IL-17RA, } \\
& & IL-17RE, IL-17RC & $($ 48-50) \\
miR-181a/b & Cell apoptosis, cell proliferation & PCAF & PCAF \\
miR-106b-25 cluster & Cell apoptosis, cell proliferation & PCAF & $(36)$ \\
miR-32 & Cell apoptosis, cell proliferation & SMAD5 \\
miR-135b & Cell differentiation & P53 & $(36)$ \\
miR-125a & Cell apoptosis, cell proliferation & TIMP2 & $(54)$ \\
miR-301a & Cell apoptosis, cell proliferation & & $(36)$ \\
\hline
\end{tabular}

miR, microRNA; MM, multiple myeloma; p27Kip1, cyclin dependent kinase inhibitor 1B; p57Kip2, cyclin-dependent kinase inhibitor 1C; PUMA, BCL2 binding component 3; PTEN, phosphatase and tens in homolog; BIM, BCL2 like 11; SOCS1, suppressor of cytokine signaling 1; IL-17, interleukin-17; PCAF, p-300-CBP associated factor; SMAD5, SMAD family member 5; P53, tumor protein p53; TIMP2, TIMP metallopeptidase inhibitor 2; Refs., references.

Table III. Principal tumor suppressor microRNAs downregulated in MM.

\begin{tabular}{lll}
\hline MicroRNAs & \multicolumn{1}{c}{ Cell processes } & \multicolumn{1}{c}{ Validated target genes } \\
\hline $\begin{array}{l}\text { miR-125b } \\
\text { Let-7b }\end{array}$ & Cell apoptosis, cell proliferation & Refs. \\
miR-29 family & Cell apoptosis, cell proliferation & IRF4 \\
& Cell apoptosis, cell proliferation, & IGF-1R \\
miR-34a & cell migration & DNMT3A, DNMT3B, PSME4, \\
miR-202 & Cell apoptosis, cell proliferation & Sp1, CDK6, MCL-1 \\
miR-15a/16 & Cell apoptosis, cell proliferation & NOTCH1, BCL2, CDK6 \\
miR-214 & Cell apoptosis, cell proliferation, cell migration, & FGFR1, PIK3, PI3KC2A, \\
miR-192, 194,215 & cell cycle, angiogenesis & MDM4, VEGF \\
miR-33b & Cell apoptosis, cell proliferation, cell cycle & PSMD10, ASF1B \\
miR-126 & Cell apoptosis, cell proliferation, cell cycle & MDM2, IL-17R \\
miR-130b & Cell apoptosis, cell proliferation, cell migration & PIM-1 \\
\hline
\end{tabular}

miR, microRNA; MM, multiple myeloma; IRF4, interferon regulatory factor 4; IGF-1R, insulin-like growth factor 1 receptor; DNMT, DNA methyltransferase; PSME4, Proteasome activator complex subunit 4; FGFR1, Fibroblast growth factor receptor 1; VEGF, Vascular endothelial growth factor; PSMD10, 26S proteasome non-ATPase regulatory subunit 10; ASF1B, anti-silencing function 1B histone chaperone; Sp1, stimulatory protein 1; CDK6, cyclin dependent kinase 6; MCL-1, myeloid cell leukemia-1; NOTCH1, Notch homolog 1; BCL2, B-cell lymphoma 2; BAFF, B cell activating factor belonging to the TNF family; C-MYC, v-myc avian myelocytomatosis viral oncogene homolog; PIK3 $\alpha$, phosphatidylinositol-4,5-bisphosphate 3-kinase catalytic subunit $\alpha$; PIK3C2A, phosphatidylinositol-4-phosphate 3-kinase catalytic subunit type 2 $\alpha$; MDM4, MDM4, p53 regulator; MDM2, MDM2 proto-oncogene; IL, interleukin; PIM-1, pim-1 proto-oncogene, serine/threonine kinase; GR- $\alpha$, glucocorticoid receptor $\alpha$; Refs., references.

associated agonist of cell death, and caspase-9 by reducing the interaction of AKT and its substrate glycogen synthase kinase $3 \beta$, which led to the limitation of cell proliferation and an increase of cell apoptosis (62). Because of these significant tumor inhibitory effects, miRNA-29b has potential in clinical application as a micromolecular nucleic acid drug. There have been numerous in vivo studies that combine clinical routine chemotherapy drugs with miRNAs. The results concluded that miRNA-29b additionally possesses a strong tumor inhibitory effect in vivo (78). In addition, this miRNA family is considered to be associated with complications in MM. Rossi et al (79) revealed that miR-29b expression declined alongside osteoclast differentiation, and its negative regulation of osteoclast activity may overcome the strong pro-osteoclastic stimuli provided by MM cells. Another previous study indicated that the expression of miR-29c is negatively correlated with the severity of renal failure and the expression level of $\beta 2$-microglobulin $(\beta 2-\mathrm{M})$, but the precise mechanism remains yet to be fully understood (80).

miR $-181 a / b$. miR-181a/b, located in chromosome $1 \mathrm{q} 32.1$, is reported to be upregulated in the malignant PCs of MGUS and MM. This upregulation suggests that miR-181a/b may be 
Table IV. Studies evaluating the diagnostic values of miRNAs using ROC analysis.

\begin{tabular}{|c|c|c|c|c|c|c|}
\hline Name & Sample & Sensitivity (\%) & Specificity (\%) & AUC & Cut-off value & Refs. \\
\hline miR-720 & MM/MG vs. N & 87.2 & 92.3 & 0.9112 & $5,773.0000$ & $(85)$ \\
\hline $\operatorname{miR}-1308$ & MM/MG vs. N & 82.1 & 92.3 & 0.8920 & $405,400.0000$ & $(85)$ \\
\hline miR-720+miR-1308 & MM vs. MG & 97.4 & 92.3 & 0.9862 & 83.9000 & $(85)$ \\
\hline miR-1246+miR-1308 & MM vs. MG & 79.2 & 66.7 & 0.7250 & 6.4000 & $(85)$ \\
\hline miR-29a & MM vs. $\mathrm{N}$ & 88.0 & 70.0 & 0.8320 & 0.0103 & $(86)$ \\
\hline miR-483 & MM vs. N & 50.0 & 90.0 & 0.7450 & 12.6900 & $(87)$ \\
\hline miR-20a & MM vs. N & 63.0 & 85.0 & 0.7400 & 478.9000 & $(87)$ \\
\hline miR-34a+Let-7e & MM vs. N & 80.6 & 86.7 & 0.8980 & ND & $(14)$ \\
\hline miR-19a+miR-4254 & MM vs. $\mathrm{N}$ & 91.7 & 90.5 & 0.9500 & ND & $(43)$ \\
\hline miR-15a & MM vs. $\mathrm{N}$ & 100.0 & 73.0 & 0.8640 & 2.3500 & $(88)$ \\
\hline miR-16-1 & MM vs. N & 78.9 & 56.7 & 0.6640 & 3.1300 & $(88)$ \\
\hline miR-214 & $\begin{array}{l}\text { MM with BD vs. } \\
\text { MM without BD }\end{array}$ & 97.0 & 86.0 & 0.7670 & ND & $(35)$ \\
\hline $\operatorname{miR}-135 b$ & $\begin{array}{l}\text { MM with BD vs. } \\
\text { MM without BD }\end{array}$ & 100.0 & 73.0 & 0.9070 & ND & $(35)$ \\
\hline
\end{tabular}

miRNA/miR, microRNA; ROC, receiving operator characteristic; AUC, area under the curve; MM, patients with multiple myeloma; MG, patients with monoclonal gammopathy of undetermined significance; N, normal controls; BD, bone diseases; ND, not determined; Refs., references.

involved in the primary pathological course of MM $(34,38)$. In MM, the P53 protein may inhibit proliferation and promote the apoptosis of tumor cells. The underlying mechanism may be attributed in part to the fact that P53 may arrest the cell cycle at the G1/S point and accelerating the DNA repairing process. Generally, the P53 gene mutation is observed in the progression from MM to plasma cell leukemia. miR-181a/b serves an important function in regulating P53. A number of studies have revealed that $\mathrm{miR}-181 \mathrm{a} / \mathrm{b}$ may negatively regulate the expression of P-300-CBP associated factor (PCAF), antagonize the positive effect of PCAF on P53, and eventually result in the decreased expression of P53 (36). Additionally, miR-181a/b may work as a histone acetyltransferase to keep P53 at a low level or partially inactivated by controlling its stability through human double minute 2. Furthermore, miR-181a/b is abnormally expressed in two drug-resistance MM cell lines (U266 Dox resistant and 8226 Dox resistant) (81), suggesting that miR-181a/b may participate in the drug-resistance course of MM, but the underlying mechanisms remain unclear.

miR-21. miR-21, located in chromosome 17q23.2, is one of the most important onco-miRNAs in MM and its expression is significantly elevated in the malignant PCs of MM (82). miR-21 is closely associated with the bone marrow microenvironment. IL6, secreted by bone marrow mesenchymal stem cells (BMSCs) may induce an elevated expression of miR-21 through activating the STAT3 signaling pathway. Zheng et al (83) revealed that, in MM cells, miR-21 expression was positively correlated with an abnormally increased expression of proteasome subunit $\beta 4$ which may promote the growth and proliferation of MM cells by stimulating the NFkB-miR-21 signaling pathway. miR-21 is not only associated with the malignant behavior of MM cells, but is additionally involved in the drug-resistance behavior of MM cells. It is partly due to the fact that miR-21 may target oncogene ras homolog gene family member B and stimulate the
$\mathrm{NF} \kappa \mathrm{B}$ signaling pathway, and then overcomes BMSC induced drug-resistance of MM. Increasingly, evidence suggests that miR-21 may become a novel therapeutic target for patients with MM with severe drug-resistance (84).

\section{3. miRNAs as potential diagnostic biomarkers of MM}

Bone marrow biopsy is the gold standard for the clinical diagnosis of MM. However, this traditional diagnostic method is invasive and is a painful procedure for patients. It is urgent to identify a more sensitive, convenient and noninvasive biomarker to apply in the clinical diagnosis of MM. ROC curve analysis provides a regular way to assess the value of diagnosis. Here, studies evaluating the diagnostic values of miRNAs have been summarized in Table IV $(14,35,43,85-88)$.

miRNAs may distinguish patients with MM from HDs. Extracellular free miRNAs are protected by tiny vesicles, exosomes, particles and apoptosis bodies, or bind to proteins in serum, plasma, saliva, urine and other body fluids to avoid being degraded (89). This feature means that miRNAs possess the potential to be indicators of MM in clinical applications (90). Jones et al (85) obtained a series of miRNAs whose expression differed between patients with MM and HDs through gene array analysis of the peripheral serum in patients with MM and conducted a large-scale validation for three miRNAs (miR-720, miR-1308 and miR-1246) with a relatively large difference of expression between them. ROC curve analysis revealed that serum miR-720 yielded an area under the curve (AUC) of $0.9112(\mathrm{P}<0.001)$ with $87.2 \%$ sensitivity and $92.3 \%$ specificity for discriminating patients with MGUS and MM from healthy controls. A combination of miR-1308 and miR-720 provided a more powerful diagnostic effect with the AUC rising to 0.9862, with a sensitivity of $97.4 \%$ and specificity of $92.3 \%$. Another previous study indicated that miR-142-5p, miR-660 and miR-29a 
were upregulated in the serum of patients with MM (86). Further ROC curve analysis demonstrated that serum miR-29a expression possessed a potent ability in discriminating patients with MM from HDs with an AUC of 0.8320, with $88.0 \%$ sensitivity and $70.0 \%$ specificity. Qu et al (87) discovered that serum miR-483-5p and miR-20a possessed a considerable diagnostic efficacy yielding an AUC of 0.7450 (sensitivity $58.0 \%$, specificity $90.0 \%$ ) and 0.7400 (sensitivity $63.0 \%$, specificity $85.0 \%$ ), respectively. Furthermore, a previous study concluded that the combined application of the serum expression of miR-19a with miR-4254 had a significant diagnostic value with an AUC of 0.9500 , with a sensitivity of $91.7 \%$ and specificity of $90.5 \%$ (43).

These studies utilizing ROC analysis suggest that miRNAs possess considerable diagnostic efficacy as serological markers for MM, and have advantages over traditional diagnostic methods, including convenience and noninvasiveness. Despite the fact that the preliminary results are positive, larger samples are required for further validation. Additionally, the methods of specimen collection, RNA extraction and data analysis varied between different studies, and it is necessary to set up a unified standard in the process of testing.

Correlation between miRNAs and clinical parameters of $M M$. miRNAs are closely associated with the occurrence and development of MM and their expression levels are significantly correlated with a number of common laboratory biomarkers of MM (91). Therefore, miRNAs may be used as indicators to reflect the severity of MM. It was identified that serum miR-214 and miR-135b expression levels had the ability to distinguish between patients with MM with or without bone disease and may reflect the severity of bone lesions (35). The AUC of miR-214 was 0.767 with $97 \%$ sensitivity and $86 \%$ specificity, and the serum level of miR-135b was a powerful diagnostic tool in the identification of $\mathrm{MM}$ associated bone diseases with an AUC of 0.907 , sensitivity of $100 \%$ and specificity of $73 \%$. Additionally, these two miRNAs were positively correlated with the severity of bone disease. Kubiczkova et al (14) revealed that serum miR-744, miR-130a, let-7d, and let-7e levels were positively correlated with hemoglobin levels in patients with MM and the expression levels of miR-744, miR-130a, let-7d, and let-7e were positively correlated with the thrombocyte count and significantly negatively correlated with creatinine and $\beta-2$ microglobulin levels. Furthermore, the expression levels of miR-744, let-7d and let-7e were positively associated with albumin levels and miR-744, let-7e were negatively associated with $\mathrm{C}$-reactive protein. Only the let-7e expression was negatively correlated with monoclonal immunoglobulin levels.

miRNAs possess advantages in sensitivity and specificity of detection compared with conventional hematological auxiliary diagnostic indicators. Furthermore, one abnormally expressed miRNA may have a correlation with multiple conventional hematological parameters (14). This quality will increase their convenience for clinical application. A number of miRNAs were also significantly associated with imagological examination. A previous study investigated the ability of miR-214 and miR-135b to distinguish between patients with MM with and without bone disease using the ROC analysis and it was revealed that they possess greater potential as an alternative of imageological examination due to the fact that they are more convenient and economical (35).

\section{4. miRNAs as potential prognostic biomarkers of MM}

MM is a hematological tumor with obvious heterogeneity. Patients with different stages and classifications vary in therapeutic strategies and clinical outcomes. Clinical research on the prognosis of MM has been continuously progressing. Presently, commonly used indicators for prognosis of MM are usually based on cytogenetic abnormities including Translocation/Cyclin D (TC), International Staging System (ISS) and fluorescence hybridization (FISH) of malignant PCs, and gene expression profiling (GEP) (92). These classification methods have clinical effectiveness to some extent, but cannot accurately reflect all genetic mutations during the process of MM. miRNAs may regulate almost all cellular processes with a more comprehensive reflection of the dysfunctional state of patients with MM. Therefore, miRNAs are more likely to become novel effective biomarkers for predicting the prognosis of MM patients. Table V $(14,15,35,43,87,88,93,94)$ summarizes studies evaluating the prognostic values of miRNAs using survival analysis.

Correlation of miRNAs and conventional prognostic biomarkers of MM. Wu et al (95) analyzed miRNA expression profiling in $\mathrm{CD} 138^{+}$cells from the bone marrow tissues of patients with $\mathrm{MM}$ and followed them up. A distinct upregulation of the miRNA cluster miR-99b/let-7e/miR-125a on 19q was identified in TC $4 \mathrm{p} 16$ cases, and additionally miR-150/miR-155/miR-34a were upregulated in the MAF subgroup. An outcome scale model was established based on the combined application of miR-17 and miR-886-5p, and patients were divided into high-, moderate- and low-risk groups $(\mathrm{P}=0.001)$ according to their overall survival (OS). The prediction accuracy of the combined application of these two miRNAs is $98.46 \%$, much greater than that of the outcome scale approach based on ISS/FISH $(\mathrm{P}=0.0004)$. This novel outcome scale mode based on miRNAs was also able to identify that patients with MM carrying the $\mathrm{t}(4 ; 14)$ mutation and patients carrying the $\mathrm{t}(4 ; 14)$ mutation with a lower expression of these two miRNAs had a longer OS (71 months). Additionally, Huang et al (93) conducted FISH tests in malignant PCs and then detected miRNA expression levels in plasma of patients with MM. The expression level of miR-99b in the plasma of patients with MM was revealed to be significantly correlated with $\mathrm{t}(4 ; 14$; immunoglobulin heavy locus; fibroblast growth factor receptor 3) translocation and the low expression of miR-221 was significant associated with del(13q14). Qu et al (87) observed the significantly association between plasma miR-483-5p expression levels and the ISS stage. Furthermore, Kubiczkova et al (14) revealed that serum miR-744, let-7d, and let-7e expression levels were positively correlated with ISS staging in patients with MM and serum let-7e expression level was significantly associated with del (13q14) obtained from the FISH tests of MM PCs.

These results indicated that miRNAs have a huge potential to function as prognostic indicators. Furthermore, as they may be detected more conveniently, circulating miRNAs may offer an advantage over the traditional FISH detection of malignant PCs in bone marrow.

Survival analyses of miRNAs in MM. In addition to being associated with conventional prognostic markers, long-term follow-up studies may reveal the association between miRNA 
Table V. Studies evaluating the prognostic values of miRNAs using survival analysis.

\begin{tabular}{|c|c|c|c|c|}
\hline Name & P-value & HR $(95 \% \mathrm{CI})$ & Method & Refs. \\
\hline \multicolumn{5}{|l|}{ RFS } \\
\hline miR-20a & 0.0100 & ND & $\mathrm{K}-\mathrm{M}$ & $(93)$ \\
\hline miR-148a & 0.0200 & ND & $\mathrm{K}-\mathrm{M}$ & $(93)$ \\
\hline \multicolumn{5}{|l|}{ PFS } \\
\hline $\operatorname{miR}-25$ & 0.0340 & $0.920(0.840,0.990)$ & Univariate Cox regression & $(94)$ \\
\hline $\operatorname{miR}-483$ & 0.0250 & ND & $\mathrm{K}-\mathrm{M}$ & $(87)$ \\
\hline miR-33b & 0.0160 & ND & Univariate Cox regression & $(15)$ \\
\hline miR-19 & 0.0030 & $2.787(1.421,5.468)$ & Multivariable Cox regression & $(43)$ \\
\hline miR-15a & 0.0080 & $0.260(0.090,0.710)$ & Multivariable Cox regression & $(88)$ \\
\hline $\operatorname{miR}-214$ & 0.0150 & ND & $\mathrm{K}-\mathrm{M}$ & $(35)$ \\
\hline \multicolumn{5}{|l|}{ OS } \\
\hline miR-25 & 0.0005 & $0.810(0.720,0.910)$ & Univariate Cox regression & $(94)$ \\
\hline $\operatorname{miR}-25$ & 0.0130 & $0.760(0.620,0.940)$ & Multivariable Cox regression & $(94)$ \\
\hline miR-744 & 0.0001 & $0.670(0.548,0.819)$ & Univariate Cox regression & $(14)$ \\
\hline Let-7e & 0.0020 & $0.611(0.450,0.829)$ & Univariate Cox regression & $(14)$ \\
\hline miR-33b & 0.0330 & ND & Univariate Cox regression & $(15)$ \\
\hline miR-19 & 0.0230 & $2.995(1.167,7.690)$ & Multivariable Cox regression & $(43)$ \\
\hline $\operatorname{miR}-15 a$ & 0.0350 & $0.280(0.080,0.930)$ & Multivariable Cox regression & $(88)$ \\
\hline miR-214 & 0.0020 & ND & $\mathrm{K}-\mathrm{M}$ & $(35)$ \\
\hline
\end{tabular}

miRNA/miR, microRNA; HR, hazard ratio; CI, confidence interval; ND, not determined; RFS, relapse-free survival; PFS, progression-free survival; OS, overall survival; K-M, Kaplan-Meier method; multivariable Cox regression, multivariable Cox proportional hazards regression model, univariate Cox regression, univariate Cox proportional hazards regression model; Refs., references.

expression and the life expectancy of patients with MM directly. Huang et al (93) assessed the association between plasma miRNAs and the life expectancy of patients using Kaplan-Meier survival curves. Results demonstrated that high expression levels of plasma miR-20a and miR-148a in patients with MM were significantly correlated with relapse-free survival ( $\mathrm{P}=0.01$ and $\mathrm{P}=0.02$, respectively). Rocci et al (94) selected ten miRNAs which had stable serum expression for a follow-up study. Results indicated that patients with MM with higher levels of miR-25 [hazard ratio $(\mathrm{HR})=0.81 ; \mathrm{P}=0.0005$ ], miR-16 $(\mathrm{HR}=0.87 ; \mathrm{P}=0.008)$ and $\mathrm{miR}-30 \mathrm{a}(\mathrm{HR}=0.86, \mathrm{P}=0.016)$ in their serum had a longer OS than those with a lower expression of these miRNAs. Furthermore, serum miR-25 expression level was significantly correlated with progression-free survival (PFS; $\mathrm{P}=0.034$ ). Additionally, it was concluded that miR-25 and miR-16 were independent prognostic indicators for the OS of newly diagnosed patients with MM using Cox regression analysis. Hao et al (35) reported that the high expression of serum miR-21 may be an effective indicator of the poor outcomes in patients with MM. Patients with high expression level of serum miR-214 had significant shortened PFS $(\mathrm{P}=0.015)$ and $\mathrm{OS}(\mathrm{P}=0.002)$ compared with those with a low expression level.

miRNAs have proved to be effective indicators in survival analysis and risk evaluation. The next step of these studies should focus on validating these biomarkers in larger samples and then combining utilization with conventional prognostic markers including ISS, FISH and GEP to improve the accuracy of risk stratification and outcome prediction.
miRNAs used for predicting of therapeutic response in MM. Patients with MM have varied therapeutic responses and a number of patients are resistant to one or more chemotherapy drugs, which bring a number of difficulties to clinical treatment. It is imperative to discover novel clinical indicators that may effectively predict the therapeutic efficacy. ASCT is a recognized effective therapy for MM, but its therapeutic efficacy remains different for different individuals. Navarro et al (96) investigated the difference of serum miRNA expression profiling in patients with MM prior to and following performing ASCT. Results indicated that patients with a high expression of serum miR-19b and miR-331 had significantly prolonged PFS subsequent to receiving ASCT $(\mathrm{P}<0.001$ and $\mathrm{P}=0.001$, respectively) and combined application of these two miRNAs may be a more effective predicting indicator for PFS following ASCT $(\mathrm{HR}=5.3, \mathrm{P}=0.033)$. Hao et al (43) identified that patients with a low expression of serum miR-19a had an improved therapeutic response to bortezomib (BZ) and significantly extended PFS and OS following BZ treatment $(\mathrm{P}=0.002)$, whereas patients with a high expression of serum miR-19a had no obvious efficacy and no improvement in survival analysis. Li et al (88) investigated whether miR-15a downregulated in bone marrow tissues may influence the response of patients to different therapies. It was revealed that therapy based on thalidomide and BZ may not remarkably improve the PFS and OS of patients with a low-expression of miR-15a. Another previous study on miRNA expression profiling analysis associated with serum exosomes revealed that the expression levels of serum exosome derived miR-16-5p, miR-15a-5p, miR-20a-5p and miR-17-5p 
had increased 3.91, 1.83, 2.96 and 1.97 times, respectively, in the BZ-effective group compared with those in the BZ-resistant group (97).

These previous studies suggest that different miRNA expression profiling are significantly associated with the varied therapeutic responses of patients and may be used as predicting indicators to monitor therapeutic responses in patients with MM. In addition, these miRNAs may also provide an important basis for individual treatment.

Dynamics of miRNA levels during MM progression. As deregulated miRNA expression in patients with MGUS and MM was observed at the time of diagnosis, the further aim for researchers was to check if this profiling changed during disease progression. Kubiczkova et al (14) collected serum samples at the time of diagnosis and relapse (following 2 lines of treatment), and revealed that almost all miRNAs in MM samples were significantly different from HDs (miR-744: $\mathrm{FC}=0.270$, miR-130a: $\mathrm{FC}=0.487$, miR-34a: $\mathrm{FC}=10.083$, let-7d: $\mathrm{FC}=0.243$, let-7e: $\mathrm{FC}=0.300$ ). Furthermore, a significant increase of miR-34a $(\mathrm{P}<0.0001, \mathrm{FC}=3.560)$ and decrease of let-7d $(\mathrm{P}=0.0182$, $\mathrm{FC}=0.460)$ were revealed in relapsed samples compared with samples at the time of first diagnosis. Yyusnita et al (40) claimed that four miRNAs (miR-494, 130a, let-7i, let-7c) in peripheral blood samples were exclusively expressed in novel MM cases whereas nine (miR-148a, 1225, 423, 484, 99a, 106a, 224, 638, let-7b) were exclusively expressed in follow-up MM cases. Hao et al (43) indicated that miR-19a and miR-4254 expression levels were closer to the levels in HDs when in a remission phase. However, downregulated miR-19a and upregulated miR-4254 levels returned to diagnostic levels during relapse. These results demonstrated that the expression of miRNAs varied in patients with different stages of MM and had utility in monitoring MM progression.

\section{5. miRNA-based therapeutic strategies in MM}

With the exception of ASCT, traditional therapies of MM are usually based on the combined treatment of multiple chemotherapy drugs, including immunomodulatory drugs (lenalidomide and thalidomide), proteasome inhibitors (BZ), alkylating agents (melphalan and cyclophosphamide), and steroid hormones (dexamethasone). In spite of advances in present therapies, a low remission rate and drug-resistance towards the traditional chemotherapy regimen in patients with MM often result in difficulties in the clinical cure of this disease. Multiple signaling pathways may enhance the growth, proliferation, survival and migration of MM cells, and additionally induce the drug-resistance of MM cells in the pathological process of MM (98). miRNA-based therapy may selectively downregulate genes involved in the pathological processes of MM. In addition to targeting genes effectively, this therapy has the advantage of being safer. Gallo Cantafio et al (99) studied the pharmacokinetics and pharmacodynamics of the 13-merLNA-inhibitor-miR-221. The results of this previous study indicated that LNA-i-miR-221 harbored a short half-life, optimal tissue bioavailability and minimal urine excretion in mice and monkeys and revealed no toxicity in the pilot monkey study. Therefore, miRNA-based therapy is a promising novel therapeutic method for MM $(100,101)$.
miRNAs as novel drugs used in MM. miRNAs may regulate the growth of tumor cells through suppressing target gene expression. This therapeutic strategy has proved effective in vivo by an increasing number of studies. Di Martino et al (65) confirmed that miR-34a had a significant tumor inhibitory effect on severe combined immunodeficient (SCID) mice. First, miR-34a was proved to downregulate oncogenic expression, including BCL2, apoptosis regulator, cyclin dependent kinase 6 and Notch 1, at mRNA and protein levels in vitro. MM cells overexpressed miR-34a demonstrated growth inhibition, low colony formation activity and increased apoptosis. Next, in in vivo studies, researchers conducted a xenograft tumor experiment through transfecting MM cells with lentiviral miR-34a over-expression vector then injecting these cells in SCID mice. Lentiviral vector-transduced MM xenografts with constitutive miR-34a expression demonstrated high growth inhibition in SCID mice with a significant inhibition of tumor formation $(\mathrm{P}<0.05)$ and the decrease of the tumor average size $(\mathrm{P}=0.008)$. Subsequently, in order to investigate the anti-tumor effect of lipid-formulated miR-34a, miR-34a or miR-NC were administered into neutral lipid emulsion (NLE) particles and make a systemic delivery of oligonucleotides in mice. Results indicated that, after 21 days, tumors were inhibited in $50 \%$ of mice treated with formulated miR-34a mimics. In addition, a prolongation of survival time $(\mathrm{P}=0.0009)$ was observed in mice treated with miR-34a mimics compared with control groups. Additionally, a biopolymeric 3D scaffold constructed by MM cells and BMSCs was implanted into SCID mice to simulate a bone marrow microenvironment-dependent effect on MM cells. The significant inhibition of tumor growth $(\mathrm{P}<0.01)$ and prolonged survival $(\mathrm{P}=0.041)$ were observed in mice with miR-34a overexpression, which indicated that miR-34a may overcome the protective function of BMSCs for MM cells and suppress tumors.

Therapeutic effects of miRNAs were dependent on different vectors, including lentivirus, liposome and NLE. Furthermore, compared with traditional chemotherapeutic drugs, miRNAs have the obvious therapeutic efficacy in vivo without toxic reaction, release of inflammatory factors or other drug side effects.

Advantages of combined application of miRNAs and chemotherapy drugs. Previous studies indicated that the combined use of chemotherapy drugs and miRNAs may improve the therapeutic efficacy compared with a single application of one miRNA or chemotherapy drug and reduced drug-resistance of traditional chemotherapy drugs.

Glucocorticoid (GC) is frequently included in the chemotherapeutic regimen for lymphoid malignant tumors because of its capability for killing lymphoid cells. In the long-term, high-dose $\mathrm{GC}$ will result in the reduction of glucocorticoid receptors (GR), and then induce resistance to GC. However, low-dose GC does not have enough therapeutic efficacy. Palagani et al (102) investigated the possibility of improving this situation using a miRNA combined application with GC. The results of this previous study confirmed that the miR-150 synthetic vector combined with low-dose GC had a synergistic therapeutic effect on MM cells by markedly raising the cell sensitivity for GC-induced death. Furthermore, miR-150 may induce the specific response of GR via indirectly regulating the mRNAs of the proteins interacting with GR, including hormone receptors, molecular chaperones, unfolded protein stress and transcriptional 
factors, so that resistance to GC is unlikely to occur. In addition, miR-150 in tiny vesicles may also be considered to be a monitoring biomarker of therapeutic response to GC (103). Zhao et al (50) reported that mir-221/222 family expression was elevated in GC-resistance cell lines MM1R and further study verified that this miRNA family reduced the drug-resistance of MM cells to dexamethasone (Dex) and promoted the survival of MM cells by BCL2 binding component 3/BCL2 antagonist/killer 1/BCL2 associated $\mathrm{X}$, apoptosis regulator signaling pathway. Therefore, miR-221/222 antagonists may be promising therapeutic targets for reversing the drug-resistance of MM cells to Dex. Subsequently to the construction of a xenograft tumor model in SCID mice, mice treated with miR-221/222 antagonist and Dex had significantly longer survival than the mice treated only with Dex $(\mathrm{P}<0.05)$. In addition, Gulla et al (48) reported that the inhibition of miR-221/222 may restore melphalan sensitivity in MM and induced apoptosis of MM cells in vitro. It was also revealed LNA-i-miR-221 may perform anti-MM activity by systemic delivery in vivo. They demonstrated the rationale of the combined use of LNA-i-miR-221 and melphalan in drug-refractory stage of patients with MM.

BZ may inhibit the formation of proteasome, so that misfolded and short-lived proteins may not be eliminated, leading to the death of tumor cells eventually. At present, BZ has been widely used in the standard treatment regimen of MM, but BZ has a number of side effects. For example, the enhanced accumulation of polyubiquitin in cells results in an increase of protein aggregation and autophagosome to eliminate excessive polyubiquitin. This autophagy behavior eventually contributes to the occurrence of drug-resistance in tumor cells. Therefore, it is warranted to seek a type of chemotherapy drug that may eliminate proteasomes in cells without increased protective autophagy behavior. Jagannathan et al (59) identified that the increased expression of miR-29b reinforced the BZ-induced aggregation of polyubiquitin without inducing the formation of a protein autophagosome. miR-29b may result in proteasome degradation and cell death by targeting proteasome activator subunit 4 , and this pattern does not affect the accumulation of ubiquitinated proteins and is different from the mechanism of BZ-induced proteasome degradation. Additionally, the combined application of miRNA with BZ may decrease drug-resistance to BZ. A previous study concerning miR-29b and BZ disclosed that miR-29b with transcription factor Sp1 transcription factor may increase the sensitivity of MM cells to BZ and led to the increased apoptosis of MM cells through the PI3K-AKT signaling pathway (62). The group treated with BZ and miR-29b had a significantly enhanced effect on cell apoptosis, compared with the control group $(\mathrm{P}<0.01)$. Furthermore, Wang et al (84) reported that miR-21 combined with BZ, Dex, and doxorubicin (Dox) had a synergistic effect in killing MM cells and were demonstrated to be more effective than the application of any drug alone.

PRIMA- $1^{\text {Met }}$ is a novel micromolecular chemotherapy drug (104). The therapeutic efficacy of the combination of PRIMA-1 ${ }^{\text {Met }}$ with miR-29a for MM treatment was previously studied (105). miR-29a was considered to be a TS-miRNA and served an important function in the PRIMA- $1^{\text {Met }}$ induced cell apoptosis by targeting the C-MYC gene. Further xenograft tumor experiments on SCID mice verified that miR-29a combined with PRIMA-1 $1^{\text {Met }}$ may significantly inhibit the growth of tumors and the extended survival time of SCID mice, which provided a novel therapeutic strategy for the treatment of MM.

Preliminary basic studies of miRNAs in the treatment of MM have made progress, but its clinical application remains in its infancy and faces several challenges. Tumor formation and treatment duration in animal models are markedly different from those in human beings. It remains unclear if miRNAs exert a similar effect and long-term function in human beings. Furthermore, vectors that deliver miRNAs in vivo remain to be improved. It should be ensured that during the process of delivering, carriers are safe and produce no toxic or other side effects, and transported nucleic acid molecules are stable without degradation by endogenic nuclease, which requires more effective chemical modification technology to improve current vectors for clinical application.

\section{Conclusion}

Basic studies of tumors has always been an area of concentrated research, but the transformation from preliminary basic studies to clinical application is a problem at present. A number of researchers put forward the concept of 'Theragnostics', representing cutting-edge, multi-disciplinary strategies that combine diagnostics with therapeutics in order to generate personalized therapies and improve the outcomes of tumor patients (13). Application of theragnostics in patients with clinical cancer may raise their survival rate, with a more accurate diagnosis of cancer and optimized choice of treatment regimen.

Circulating miRNAs possess potential to become novel biomarkers obtained in a non-invasive manner (106), but the origin they derive from is still unclear. Furthermore, which is the best detection source out of whole blood, plasma, serum and exosomes remains controversial (89). Kubiczkova et al (14) discussed the derivation of several miRNAs in the exosomal and exosome-depleted supernatant of six newly diagnosed patients with MM. Concentration of miR-744, miR-130a, let-7d and let-7e (all $\mathrm{P}<0.05$ ) were revealed to be significantly higher in the exosome pellet compared with the exosome-depleted supernatant. Previous studies considered that exosomal miRNA profiling was superior for detecting pathology in secretory cell types. In addition, there remains a lack of standardized protocols for sample collection, small RNA extraction and data-analytical methods when quantifying miRNAs.

miRNAs and their target genes represent basic networks, regulating a variety of cellular functions and that are also the rationale of miRNA-based therapeutic strategies. However, there are multiple miRNAs targeting the same gene, thus interfering with a single miRNA may not produce enough effects; correspondingly, one miRNA may work on multiple targets, which will result in unknown side effects in the long term. Furthermore, in the delivery system, it is necessary to ascertain the right way to inject these vectors to achieve the highest efficacy in the safest manner.

\section{Acknowledgements}

Not applicable. 


\section{Funding}

The present review was supported by the National Nature Science Foundation of China (grant nos. 81301498 and 81271920), the Project of Jiangsu Provincial Department of Health and Family Planning Commission (grant no. H201526), the Project of the Jiangsu Provincial Six Talent Peaks (grant no. WS-066), the Social Science and Technology Innovation and Demonstration Project in Nantong (grant no. HS2014059) and the Innovation Project of Graduate Students of Nantong University (grant no. YKC15099).

\section{Availability of data and materials}

Not applicable.

\section{Authors' contributions}

$\mathrm{BZ}$ wrote the initial draft and designed the outline of the manuscript. HCo, SJ and XS designed the outline and revised the manuscript. HCh revised and expanded the manuscript. $\mathrm{YZ}$ and $\mathrm{XL}$ contributed to the acquisition and analysis of data for the work. All authors have seen and approved the final manuscript.

\section{Ethics approval and consent to participate}

Not applicable.

\section{Consent for publication}

Not applicable.

\section{Competing interests}

The authors declare that they have no competing interests.

\section{References}

1. Rebecca RL, Kimberly KD and Jemal A: Cancer statistics, 2018. CA Cancer J Clin 68: 7-30, 2018.

2. Durie BGM: Patient Handbook: Multiple Myeloma, Cancer of the Bone Marrow. International Myeloma Foundation, North Hollywood, CA, 2010.

3. Ailawadhi S, Aldoss IT, Yang D, Razavi P, Cozen W, Sher T and Chanan-Khan A: Outcome disparities in multiple myeloma: A SEER-based comparative analysis of ethnic subgroups. Br J Haematol 158: 91-98, 2012.

4. Rollig C, Knop S and Bornhauser M: Multiple myeloma. Lancet 385: 2197-2208, 2015.

5. Zhao Q, Luo F, Ma J and Yu X: Bone metastasis-related MicroRNAs: New targets for treatment. Curr Cancer Drug Targets 15: 716-725, 2015.

6. Rossi M, Tagliaferri P and Tassone P: MicroRNAs in multiple myeloma and related bone disease. Ann Transl Med 3: 334, 2015.

7. Rocci A, Hofmeister CC and Pichiorri F: The potential of miRNAs as biomarkers for multiple myeloma. Expert Rev Mol Diagn 14 947-959, 2014.

8. Bi CL and Chng WJ: miRNA deregulation in multiple myeloma. Chin Med J (Engl) 124: 3164-3169, 2011.

9. Ghobrial IM: Myeloma as a model for the process of metastasis: Implications for therapy. Blood 120: 20-30, 2012.

10. Cottini $\mathrm{F}$ and Anderson K: Novel therapeutic targets in multiple myeloma. Clin Adv Hematol Oncol 13: 236-248, 2015.

11. Kumar SK, Rajkumar SV, Dispenzieri A, Lacy MQ, Hayman SR Buadi FK, Zeldenrust SR, Dingli D, Russell SJ, Lust JA, et al: Improved survival in multiple myeloma and the impact of novel therapies. Blood 111: 2516-2520, 2008.
12. Kumar SK, Dimopoulos MA, Kastritis E, Terpos E, Nahi H, Goldschmidt H, Hillengass J, Leleu X, Beksac M, Alsina M, et al: Natural history of relapsed myeloma, refractory to immunomodulatory drugs and proteasome inhibitors: A multicenter IMWG study. Leukemia 31: 2443-2448, 2017.

13. Ahmad N, Haider S, Jagannathan S, Anaissie E and Driscoll JJ: MicroRNA theragnostics for the clinical management of multiple myeloma. Leukemia 28: 732-738, 2014.

14. Kubiczkova L, Kryukov F, Slaby O, Dementyeva E, Jarkovsky J, Nekvindova J, Radova L, Greslikova H, Kuglik P, Vetesnikova E, et al: Circulating serum microRNAs as novel diagnostic and prognostic biomarkers for multiple myeloma and monoclonal gammopathy of undetermined significance. Haematologica 99: 511-518, 2014

15. Li F, Hao M, Feng X, Zang M, Qin Y, Yi S, Li Z, Xu Y, Zhou L, Sui W, et al: Downregulated miR-33b is a novel predictor associated with disease progression and poor prognosis in multiple myeloma. Leuk Res 39: 793-799, 2015.

16. Shukla GC, Singh J and Barik S: MicroRNAs: Processing, maturation, target recognition and regulatory functions. Mol Cell Pharmacol 3: 83-92, 2011.

17. Zhang Q, Yan W, Bai Y, Xu H, Fu C, Zheng W, Zhu Y and Ma J: Synthetic miR-145 mimic inhibits multiple myeloma cell growth in vitro and in vivo. Oncol Rep 33: 448-456, 2015.

18. Sun Y, Pan J, Mao S and Jin J: IL-17/miR-192/IL-17Rs regulatory feedback loop facilitates multiple myeloma progression. PLoS One 9: e114647, 2014.

19. Yang Y, Li F, Saha MN, Abdi J, Qiu L and Chang H: miR-137 and miR-197 induce apoptosis and suppress tumorigenicity by targeting MCL-1 in multiple myeloma. Clin Cancer Res 21: 2399-2411, 2015.

20. Macfarlane LA and Murphy PR: MicroRNA: Biogenesis, function and role in cancer. Curr Genomics 11: 537-561, 2010.

21. Bartel DP: MicroRNAs: Target recognition and regulatory functions. Cell 136: 215-233, 2009.

22. Rossi M, Amodio N, Di Martino MT, Tagliaferri P, Tassone P and Cho WC: MicroRNA and multiple myeloma: From laboratory findings to translational therapeutic approaches. Curr Pharm Biotechnol 15: 459-467, 2014.

23. Di Martino MT, Amodio N, Tassone P and Tagliaferri P: Functional analysis of microRNA in multiple myeloma. Methods Mol Biol 1375: 181-194, 2016.

24. Raimondi L, De Luca A, Morelli E, Giavaresi G, Tagliaferri P, Tassone P and Amodio N: MicroRNAs: Novel crossroads between myeloma cells and the bone marrow microenvironment. Biomed Res Int 2016: 6504593, 2016.

25. Calin GA, Dumitru CD, Shimizu M, Bichi R, Zupo S, Noch E, Aldler H, Rattan S, Keating M, Rai K, et al: Frequent deletions and down-regulation of micro-RNA genes miR15 and miR16 at 13q14 in chronic lymphocytic leukemia. Proc Natl Acad Sci USA 99: 15524-15529, 2002

26. Pichiorri F, Suh SS, Rocci A, De Luca L, Taccioli C, Santhanam R, Zhou W, Benson DM Jr, Hofmainster C, Alder H, et al: Downregulation of p53-inducible microRNAs 192, 194 and 215 impairs the p53/MDM2 autoregulatory loop in multiple myeloma development. Cancer Cell 18: 367-381, 2010.

27. Misiewicz-Krzeminska I, Sarasquete ME, Quwaider D, Krzeminski P, Ticona FV, Paíno T, Delgado M, Aires A, Ocio EM, García-Sanz R, et al: Restoration of microRNA-214 expression reduces growth of myeloma cells through positive regulation of P53 and inhibition of DNA replication. Haematologica 98: 640-648, 2013.

28. Zhang Q, Wang LQ, Wong KY, Li ZY and Chim CS: Infrequent DNA methylation of miR-9-1 and miR-9-3 in multiple myeloma. J Clin Pathol 68: 557-561, 2015.

29. Cipolla GA, Park JK, de Oliveira LA, Lobo-Alves SC, de Almeida RC, Farias TD, Lemos Dde S, Malheiros D, Lavker RM and Petzl-Erler ML: A 3'UTR polymorphism marks differential KLRG1 mRNA levels through disruption of a miR-584-5p binding site and associates with pemphigus foliaceus susceptibility. Biochim Biophys Acta 1859: 1306-1313, 2016.

30. Zhao JJ and Carrasco RD: Crosstalk between microRNA30a/b/c/ $\mathrm{d} / \mathrm{e}-5 \mathrm{p}$ and the canonical Wnt pathway: Implications for multiple myeloma therapy. Cancer Res 74: 5351-5358, 2014.

31. Brocke-Heidrich K, Kretzschmar AK, Pfeifer G, Henze C, Löffler D, Koczan D, Thiesen HJ, Burger R, Gramatzki M and Horn F: Interleukin-6-dependent gene expression profiles in multiple myeloma INA-6 cells reveal a Bcl-2 family-independent survival pathway closely associated with Stat 3 activation. Blood 103: 242-251, 2004 
32. Leotta M, Biamonte L, Raimondi L, Ronchetti D, Di Martino MT, Botta C, Leone E, Pitari MR, Neri A, Giordano A, et al: A p53-dependent tumor suppressor network is induced by selective miR-125a-5p inhibition in multiple myeloma cells. J Cell Physiol 229: 2106-2116, 2014.

33. Shen X, Guo Y, Yu J, Qi J, Shi W, Wu X, Ni H and Ju S: miRNA-202 in bone marrow stromal cells affects the growth and adhesion of multiple myeloma cells by regulating B cell-activating factor. Clin Exp Med 16: 307-316, 2016.

34. Zhou Y, Chen L, Barlogie B, Stephens O, Wu X, Williams DR, Cartron MA, van Rhee F, Nair B, Waheed S, et al: High-risk myeloma is associated with global elevation of miRNAs and overexpression of EIF2C2/AGO2. Proc Natl Acad Sci USA 107: 7904-7909, 2010.

35. Hao M, Zang M, Zhao L, Deng S, Xu Y, Qi F, An G, Qin Y, Sui W, Li F, et al: Serum high expression of miR-214 and miR-135b as novel predictor for myeloma bone disease development and prognosis. Oncotarget 7: 19589-19600, 2016.

36. Pichiorri F, Suh SS, Ladetto M, Kuehl M, Palumbo T, Drandi D, Taccioli C, Zanesi N, Alder H, Hagan JP, et al: MicroRNAs regulate critical genes associated with multiple myeloma pathogenesis. Proc Natl Acad Sci USA 105: 12885-12890, 2008.

37. Unno K, Zhou Y, Zimmerman T, Platanias LC and Wickrema A: Identification of a novel microRNA cluster miR-193b-365 in multiple myeloma. Leuk Lymphoma 50: 1865-1871, 2009.

38. Roccaro AM, Sacco A, Thompson B, Leleu X, Azab AK, Azab F, Runnels J, Jia X, Ngo HT, Melhem MR, et al: MicroRNAs 15a and 16 regulate tumor proliferation in multiple myeloma. Blood 113 : 6669-6680, 2009.

39. Chi J, Ballabio E, Chen XH, Kušec R, Taylor S, Hay D, Tramonti D, Saunders NJ, Littlewood T, Pezzella F, et al MicroRNA expression in multiple myeloma is associated with genetic subtype, isotype and survival. Biol Direct 6: 23, 2011

40. Yyusnita, Norsiah, Zakiah I, Chang KM, Purushotaman VS, Zubaidah Z and Jamal R: MicroRNA (miRNA) expression profiling of peripheral blood samples in multiple myeloma patients using microarray. Malays J Pathol 34: 133-143, 2012.

41. Campo S, Allegra A, D'Ascola A, Alonci A, Scuruchi M Russo S, Avenoso A, Gerace D, Campo GM and Musolino C: MiRNome expression is deregulated in the peripheral lymphoid compartment of multiple myeloma. Br J Haematol 165: 801-813, 2014

42. Wang W, Corrigan-Cummins M, Barber EA, Saleh LM, Zingone A, Ghafoor A, Costello R, Zhang Y, Kurlander RJ, Korde N, et al: Aberrant Levels of miRNAs in Bone marrow microenvironment and peripheral blood of myeloma patients and disease progression. J Mol Diagn 17: 669-678, 2015.

43. Hao M, Zang M, Wendlandt E, Xu Y, An G, Gong D, Li F, Qi F, Zhang Y, Yang Y, et al: Low serum miR-19a expression as a novel poor prognostic indicator in multiple myeloma. Int J Cancer 136: 1835-1844, 2015.

44. Agarwal V, Bell GW, Nam JW and Bartel DP: Predicting effective microRNA target sites in mammalian mRNAs Elife 4: 2015 doi: 10.7554/eLife.05005.

45. Betel D, Koppal A, Agius P, Sander C and Leslie C: Comprehensive modeling of microRNA targets predicts functional non-conserved and non-canonical sites. Genome Biol 11: R90, 2010

46. Anders G, Mackowiak SD, Jens M, Maaskola J, Kuntzagk A Rajewsky N, Landthaler M and Dieterich C: doRiNA: A database of RNA interactions in post-transcriptional regulation. Nucleic Acids Res 40: D180-D186, 2012.

47. Shang J, Yao Y, Fan X, Shangguan L, Li J, Liu H and Zhou Y: miR-29c-3p promotes senescence of human mesenchymal stem cells by targeting CNOT6 through p53-p21 and p16-pRB pathways. Biochim Biophys Acta 1863: 520-532, 2016.

48. Gulla A, Di Martino MT, Gallo Cantafio ME, Morelli E, Amodio N, Botta C, Pitari MR, Lio SG, Britti D, Stamato MA, et al: A 13 mer LNA-i-miR-221 inhibitor restores drug sensitivity in melphalan-refractory multiple myeloma cells. Clin Cancer Res 22: 1222-1233, 2016.

49. Di Martino MT, Gullà A, Cantafio ME, Lionetti M, Leone E, Amodio N, Guzzi PH, Foresta U, Conforti F, Cannataro M, et al: In vitro and in vivo anti-tumor activity of miR-221/222 inhibitors in multiple myeloma. Oncotarget 4: 242-255, 2013.

50. Zhao JJ, Chu ZB, Hu Y, Lin J, Wang Z, Jiang M, Chen M, Wang X, Kang Y, Zhou Y, et al: Targeting the miR-221-222/ PUMA/BAK/BAX pathway abrogates dexamethasone resistance in multiple myeloma. Cancer Res 75: 4384-4397, 2015.
51. Galm O, Yoshikawa H, Esteller M, Osieka R and Herman JG: SOCS-1, a negative regulator of cytokine signaling, is frequently silenced by methylation in multiple myeloma. Blood 101: 2784-2788, 2003.

52. Chen L, Li C, Zhang R, Gao X, Qu X, Zhao M, Qiao C, Xu J and Li J: miR-17-92 cluster microRNAs confers tumorigenicity in multiple myeloma. Cancer Lett 309: 62-70, 2011.

53. Peng J, Thakur A, Zhang S, Dong Y, Wang X, Yuan R, Zhang K and Guo X: Expressions of miR-181a and miR-20a in RPMI8226 cell line and their potential as biomarkers for multiple myeloma. Tumour Biol 36: 8545-8552, 2015.

54. Xu S, Cecilia SG, De Veirman K, Vande Broek I, Leleu X, De Becker A, Van Camp B, Vanderkerken K and Van Riet I: Upregulation of miR-135b is involved in the impaired osteogenic differentiation of mesenchymal stem cells derived from multiple myeloma patients. PLoS One 8: e79752, 2013.

55. Liang B, Yin JJ and Zhan XR: MiR-301a promotes cell proliferation by directly targeting TIMP2 in multiple myeloma. Int J Clin Exp Pathol 8: 9168-9174, 2015

56. Morelli E, Leone E, Cantafio ME, Di Martino MT, Amodio N, Biamonte L, Gullà A, Foresta U, Pitari MR, Botta C, et al: Selective targeting of IRF4 by synthetic microRNA-125b-5p mimics induces anti-multiple myeloma activity in vitro and in vivo. Leukemia 29 : 2173-2183, 2015.

57. Xu H, Liu C, Zhang Y, Guo X, Liu Z, Luo Z, Chang Y, Liu S, Sun Z and Wang $X$ : Let-7b-5p regulates proliferation and apoptosis in multiple myeloma by targeting IGF1R. Acta Biochim Biophys Sin (Shanghai) 46: 965-972, 2014.

58. Amodio N, Leotta M, Bellizzi D, Di Martino MT, D'Aquila P, Lionetti M, Fabiani F, Leone E, Gullà AM, Passarino G, et al: DNA-demethylating and anti-tumor activity of synthetic miR-29b mimics in multiple myeloma. Oncotarget 3: 1246-1258, 2012.

59. Jagannathan S, Vad N, Vallabhapurapu S, Vallabhapurapu S, Anderson KC and Driscoll JJ: MiR-29b replacement inhibits proteasomes and disrupts aggresome+autophagosome formation to enhance the antimyeloma benefit of bortezomib. Leukemia 29: 727-738, 2015.

60. Zhang YK, Wang H, Leng Y, Li ZL, Yang YF, Xiao FJ, Li QF, Chen XQ and Wang LS: Overexpression of microRNA-29b induces apoptosis of multiple myeloma cells through down regulating Mcl-1. Biochem Biophys Res Commun 414: 233-239, 2011.

61. Amodio N, Bellizzi D, Leotta M, Raimondi L, Biamonte L, D'Aquila P, Di Martino MT, Calimeri T, Rossi M, Lionetti M, et al: miR-29b induces SOCS-1 expression by promoter demethylation and negatively regulates migration of multiple myeloma and endothelial cells. Cell Cycle 12: 3650-3662, 2013.

62. Amodio N, Di Martino MT, Foresta U, Leone E, Lionetti M, Leotta M, Gullà AM, Pitari MR, Conforti F, Rossi M, et al: miR-29b sensitizes multiple myeloma cells to bortezomib-induced apoptosis through the activation of a feedback loop with the transcription factor Sp1. Cell Death Dis 3: e436, 2012.

63. Cosco D, Cilurzo F, Maiuolo J, Federico C, Di Martino MT, Cristiano MC, Tassone P, Fresta M and Paolino D: Delivery of miR-34a by chitosan/PLGA nanoplexes for the anticancer treatment of multiple myeloma. Sci Rep 5: 17579, 2015.

64. Di Martino MT, Campani V, Misso G, Gallo Cantafio ME, Gullà A, Foresta U, Guzzi PH, Castellano M, Grimaldi A, Gigantino V, et al: In vivo activity of miR-34a mimics delivered by stable nucleic acid lipid particles (SNALPs) against multiple myeloma. PLoS One 9: e90005, 2014.

65. Di Martino MT, Leone E, Amodio N, Foresta U, Lionetti M, Pitari MR, Cantafio ME, Gullà A, Conforti F, Morelli E, et al: Synthetic miR-34a mimics as a novel therapeutic agent for multiple myeloma: In vitro and in vivo evidence. Clin Cancer Res 18: 6260-6270, 2012.

66. Shen X, Guo Y, Qi J, Shi W, Wu X, Ni H and Ju S: Study on the association between miRNA-202 expression and drug sensitivity in multiple myeloma cells. Pathol Oncol Res 22: 531-539, 2016.

67. Gatt ME, Zhao JJ, Ebert MS, Zhang Y, Chu Z, Mani M, Gazit R, Carrasco DE, Dutta-Simmons J, Adamia S, et al: MicroRNAs 15a/16-1 function as tumor suppressor genes in multiple myeloma. Blood, 2010 doi: 10.1182/blood-2009-11-253294

68. Sun CY, She XM, Qin Y, Chu ZB, Chen L, Ai LS, Zhang L and $\mathrm{Hu}$ Y: miR-15a and miR-16 affect the angiogenesis of multiple myeloma by targeting VEGF. Carcinogenesis 34: 426-435, 2013.

69. Tian Z, Zhao JJ, Tai YT, Amin SB, Hu Y, Berger AJ, Richardson $\mathrm{P}$, Chauhan D and Anderson $\mathrm{KC}$ : Investigational agent MLN9708/2238 targets tumor-suppressor miR33b in MM cells. Blood 120: 3958-3967, 2012. 
70. Min DJ, Ezponda T, Kim MK, Will CM, Martinez-Garcia E, Popovic R, Basrur V, Elenitoba-Johnson KS and Licht JD: MMSET stimulates myeloma cell growth through microRNAmediated modulation of c-MYC. Leukemia 27: 686-694, 2013.

71. Tessel MA, Benham AL, Krett NL, Rosen ST and Gunaratne PH Role for microRNAs in regulating glucocorticoid response and resistance in multiple myeloma. Horm Cancer 2: 182-189, 2011.

72. Oeztuerk-Winder F, Guinot A, Ochalek A and Ventura JJ: Regulation of human lung alveolar multipotent cells by a novel p38a MAPK/miR-17-92 axis. EMBO J 31: 3431-3441, 2012.

73. Ventura A, Young AG, Winslow MM, Lintault L, Meissner A, Erkeland SJ, Newman J, Bronson RT, Crowley D, Stone JR, et al: Targeted deletion reveals essential and overlapping functions of the miR-17 through 92 family of miRNA clusters. Cell 132: 875-886, 2008.

74. Hirano T, Ishihara $\mathrm{K}$ and Hibi M: Roles of STAT3 in mediating the cell growth, differentiation and survival signals relayed through the IL- 6 family of cytokine receptors. Oncogene 19: 2548-2556, 2000.

75. Gutierrez NC, Sarasquete ME, Misiewicz-Krzeminska I, Delgado M, De Las Rivas J, Ticona FV, Fermiñán E, MartínJiménez P, Chillón C, Risueño A, et al: Deregulation of microRNA expression in the different genetic subtypes of multiple myeloma and correlation with gene expression profiling. Leukemia 24 629-637, 2010

76. Mott JL, Kobayashi S, Bronk SF and Gores GJ: mir-29 regulates Mcl-1 protein expression and apoptosis. Oncogene 26: 6133-6140, 2007.

77. Mraz M, Pospisilova S, Malinova K, Slapak I and Mayer J: MicroRNAs in chronic lymphocytic leukemia pathogenesis and disease subtypes. Leuk Lymphoma 50: 506-509, 2009.

78. Amodio N, Stamato MA, Gullà AM, Morelli E, Romeo E, Raimondi L, Pitari MR, Ferrandino I, Misso G, Caraglia M, et al: Therapeutic targeting of miR-29b/HDAC4 epigenetic loop in multiple myeloma. Mol Cancer Ther 15: 1364-1375, 2016.

79. Rossi M, Pitari MR, Amodio N, Di Martino MT, Conforti F, Leone E, Botta C, Paolino FM, Del Giudice T, Iuliano E, et al: miR-29b negatively regulates human osteoclastic cell differentiation and function: Implications for the treatment of multiple myeloma-related bone disease. J Cell Physiol 228: 1506-1515, 2013.

80. Zhang S, Wu S, Qu X, Zhao M, Xu J, Jianyong L and Lijuan C: Down-regulation of microRNA-29c is associated with renal failure in multiple myeloma. Leuk Lymphoma 55: 226-228, 2014

81. Munker R, Liu CG, Taccioli C, Alder H and Heerema N: MicroRNA profiles of drug-resistant myeloma cell lines. Acta Haematol 123: 201-204, 2010.

82. Ma J, Liu S and Wang Y: MicroRNA-21 and multiple myeloma: Small molecule and big function. Med Oncol 31: 94, 2014

83. Zheng P, Guo H, Li G, Han S, Luo F and Liu Y: PSMB4 promotes multiple myeloma cell growth by activating NF- $\mathrm{KB}-\mathrm{miR}-21$ signaling. Biochem Biophys Res Commun 458: 328-333, 2015.

84. Wang X, Li C, Ju S, Wang Y, Wang H and Zhong R: Myeloma cell adhesion to bone marrow stromal cells confers drug resistance by microRNA-21 up-regulation. Leuk Lymphoma 52: 1991-1998, 2011.

85. Jones CI, Zabolotskaya MV, King AJ, Stewart HJ, Horne GA, Chevassut TJ and Newbury SF: Identification of circulating microRNAs as diagnostic biomarkers for use in multiple myeloma. Br J Cancer 107: 1987-1996, 2012.

86. Sevcikova S, Kubiczkova L, Sedlarikova L, Slaby O and Hajek R: Serum miR-29a as a marker of multiple myeloma. Leuk Lymphoma 54: 189-191, 2013.

87. Qu X, Zhao M, Wu S, Yu W, Xu J, Xu J, Li J and Chen L: Circulating microRNA 483-5p as a novel biomarker for diagnosis survival prediction in multiple myeloma. Med Oncol 31: 219, 2014.

88. Li F, Xu Y, Deng S, Li Z, Zou D, Yi S, Sui W, Hao M and Qiu L: MicroRNA-15a/16-1 cluster located at chromosome 13q14 is down-regulated but displays different expression pattern and prognostic significance in multiple myeloma. Oncotarget 6: 38270-38282, 2015

89. Grasedieck S, Sorrentino A, Langer C, Buske C, Döhner H, Mertens D and Kuchenbauer F: Circulating microRNAs in hematological diseases: Principles, challenges and perspectives. Blood 121: 4977-4984, 2013

90. Chen X, Liang H, Zhang J, Zen K and Zhang CY: Secreted microRNAs: A new form of intercellular communication. Trends Cell Biol 22: 125-132, 2012.
91. Seckinger A, Meißner T, Moreaux J, Benes V, Hillengass J, Castoldi M, Zimmermann J, Ho AD, Jauch A, Goldschmidt H, et al: miRNAs in multiple myeloma-a survival relevant complex regulator of gene expression. Oncotarget 6: 39165-39183, 2015.

92. Bergsagel PL, Kuehl WM, Zhan F, Sawyer J, Barlogie B and Shaughnessy J Jr: Cyclin D dysregulation: An early and unifying pathogenic event in multiple myeloma. Blood 106: 296-303, 2005.

93. Huang JJ, Yu J, Li JY, Liu YT and Zhong RQ: Circulating microRNA expression is associated with genetic subtype and survival of multiple myeloma. Med Oncol 29: 2402-2408, 2012.

94. Rocci A, Hofmeister CC, Geyer S, Stiff A, Gambella M, Cascione L, Guan J, Benson DM, Efebera YA, Talabere T, et al: Circulating miRNA markers show promise as new prognosticators for multiple myeloma. Leukemia 28: 1922-1926, 2014

95. Wu P, Agnelli L, Walker BA, Todoerti K, Lionetti M, Johnson DC, Kaiser M, Mirabella F, Wardell C, Gregory WM, et al: Improved risk stratification in myeloma using a microRNA-based classifier. Br J Haematol 162: 348-359, 2013.

96. Navarro A, Diaz T, Tovar N, Pedrosa F, Tejero R, Cibeira MT, Magnano L, Rosiñol L, Monzó M, Bladé J and Fernández de Larrea C: A serum microRNA signature associated with complete remission and progression after autologous stem-cell transplantation in patients with multiple myeloma. Oncotarget 6: 1874-1883, 2015.

97. Zhang L, Pan L, Xiang B, Zhu H, Wu Y, Chen M, Guan P, Zou X, Valencia CA, Dong B, et al: Potential role of exosome-associated microRNA panels and in vivo environment to predict drug resistance for patients with multiple myeloma. Oncotarget 7 : 30876-30891, 2016.

98. Yang WC and Lin SF: Mechanisms of drug resistance in relapse and refractory multiple myeloma. Biomed Res Int 2015: 341430, 2015.

99. Gallo Cantafio ME, Nielsen BS, Mignogna C, Arbitrio M, Botta C, Frandsen NM, Rolfo C, Tagliaferri P, Tassone P and Di Martino MTL: Pharmacokinetics and pharmacodynamics of a 13-mer LNA-inhibitor-miR-221 in mice and non-human primates. Mol Ther Nucleic Acids 5: e336, 2016.

100. Zhao JJ, Lin J, Zhu D, Wang X, Brooks D, Chen M, Chu ZB, Takada K, Ciccarelli B, Admin S, et al: miR-30-5p functions as a tumor suppressor and novel therapeutic tool by targeting the oncogenic Wnt/B-catenin/BCL9 pathway. Cancer Res 74: $1801-1813,2014$

101. Guo J, McKenna SL, O'Dwyer ME, Cahill MR and O'Driscoll CM: RNA interference for multiple myeloma therapy: Targeting signal transduction pathways. Expert Opin Ther Targets 20: 107-121, 2016.

102. Palagani A, de Beeck KO, Naulaerts S, Diddens J, Sekhar Chirumamilla C, Van Camp G, Laukens K, Heyninck K, Gerlo S, Mestdagh P, et al: Ectopic microRNA-150-5p transcription sensitizes glucocorticoid therapy response in MM1S multiple myeloma cells but fails to overcome hormone therapy resistance in MM1R cells. PLoS One 9: e113842, 2014.

103. Li J,Zhang Y, Liu Y, Dai X, Li W, Cai X, Yin Y, Wang Q, Xue Y, Wang C, et al: Microvesicle-mediated transfer of microRNA-150 from monocytes to endothelial cells promotes angiogenesis. J Biol Chem 288: 23586-23596, 2013.

104. Lambert JM, Moshfegh A, Hainaut P, Wiman KG and Bykov VJ: Mutant p53 reactivation by PRIMA-1MET induces multiple signaling pathways converging on apoptosis 29: 1329-1338, 2010.

105. Saha MN, Abdi J, Yang Y and Chang H: miRNA-29a as a tumor suppressor mediates PRIMA-1Met-induced anti-myeloma activity by targeting c-Myc. Oncotarget 7: 7149-7160, 2016.

106. Besse L, Sedlarikova L, Kryukov F, Nekvindova J, Radova L, Slaby O, Kuglik P, Almasi M, Penka M, Krejci M, et al: Circulating serum MicroRNA-130a as a novel putative marker of extramedullary myeloma. PLoS One 10: e0137294, 2015.

This work is licensed under a Creative Commons Attribution-NonCommercial-NoDerivatives 4.0 International (CC BY-NC-ND 4.0) License. 